OPEN ACCESS

Edited by:

Scott McGill Nelson, University of Glasgow,

United Kingdom

Reviewed by:

Lilijana Marina,

University of Belgrade, Serbia Hang Wun Raymond Li, The University of Hong Kong, Hong Kong

*Correspondence: David B. Seifer david.seifer@yale.edu

Specialty section: This article was submitted to Reproduction, a section of the journal Frontiers in Endocrinology

Received: 10 August 2020 Accepted: 23 December 2020 Published: 09 February 2021

Citation: Kotlyar AM and Seifer DB (2021) Ethnicity/Race and Age-Specific Variations of Serum AMH in Women - A Review.

Front. Endocrinol. 11:593216. doi: 10.3389/fendo.2020.593216

\section{Ethnicity/Race and Age-Specific Variations of Serum AMH in Women -A Review}

\author{
Alexander M. Kotlyar and David B. Seifer* \\ Section of Reproductive Endocrinology and Infertility, Department of Obstetrics, Gynecology, and Reproductive Sciences, \\ Yale University, New Haven, CT, United States
}

Purpose of Review: In this review, we summarize ethnic/race- and age-related variation in $\mathrm{AMH}$ and discuss the underpinnings behind these differences.

Recent findings: Anti-mullerian hormone $(\mathrm{AMH})$ has become a widely used method of ovarian reserve testing over the last 15 years. Numerous studies have shown substantial ethnic/race and age-related differences. When compared to age-matched Caucasian women, AMH levels tend to be lower in black and Hispanic women. Chinese women tend to have significantly greater $\mathrm{AMH}$ levels prior to age 25 than Caucasian women. When considering subpopulations within ethnicities, at least one study noted lower AMH levels among Maya women compared to other Hispanic women. Age exhibits a positive trend with $\mathrm{AMH}$ up until at least 25 years of age with a consistent decline after 34 years of age extending to menopause.

Summary: $\mathrm{AMH}$ levels are highly variable among ethnicities and race with higher agematched levels typically seen in Caucasian women. Age does not exhibit a consistent linear relationship with $\mathrm{AMH}$, but a consistent decline is seen starting in the third decade of life and proceeding to menopause.

Keywords: ovarian reserve, age, race, ethnicity, $\mathrm{AMH}$, age-specific $\mathrm{AMH}$ levels

\section{INTRODUCTION}

Anti-Müllerian hormone (AMH) as a marker of ovarian reserve is an essential aspect of infertility testing. This hormone which is also known as Müllerian inhibitory substance/factor (MIS/MIF) was first discovered in 1947. Since 2002, the role of AMH/MIS has expanded from its influence on Müllerian ducts to a method of gauging a woman's ovarian reserve (1).

AMH is part of the Transforming Growth Factor-beta (TGF- $\beta$ ) group of ovarian growth factor ligands. This family includes inhibins, bone morphogenic proteins (BMPs), activins, and growth and differentiation factors (GDFs). The $2750 \mathrm{bp}$ gene for AMH is on the short arm of chromosome 19 which produces a $140 \mathrm{kDa}$ homodimer glycoprotein $(2,3)$. In-utero, AMH leads to the regression of the Müllerian ducts (4). In a male fetus, the SRY region of the Y-chromosome is expressed at approximately 8 weeks of gestation which then leads to AMH production in Sertoli cells. Once it has reached the Müllerian ducts, AMH causes the apoptosis of cells in these structures thereby leading to their regression. Due to the lack of the SRY region in female embryos, the Müllerian ducts 
continue to develop into the uterus, fallopian tubes, and upper $2 / 3$ of the vagina (5). Nonetheless, $A M H$ is produced within females and is exclusively made by the granulosa cells within pre-antral and antral follicles (6) and was discovered to be present in women's pre-ovulatory follicles in 1993 (7).

Numerous unique properties have made serum AMH a mainstay of assessing a patient's ovarian reserve. In particular, $\mathrm{AMH}$ as a measure of ovarian reserve is more reliable due to its reduced variation within each menstrual cycle and reduced interobserver variability compared to antral follicle count (AFC) and follicle stimulating hormone (FSH) levels (7-9). Additionally, AMH demonstrates minimal cycle-to-cycle variability in comparison to AFC and FSH levels $(10,11)$.

Given this greater consistency, AMH has become a widely used tool to assess ovarian reserve $(8,12)$. Furthermore, it has been studied as a tool to guide and assess the potential oocyte yield prior to ovulation induction for assisted reproductive technology (ART) cycles. The first study to demonstrate a reliable correlation between $\mathrm{AMH}$ and egg yield showed that AMH levels were 2.5 times higher in patients whose ART cycles yielded 11 or more oocytes compared to those that yielded 6 or less oocytes. This correlation between ART success and AMH was extended to live birth rates. A retrospective study looking at 1230 in-vitro fertilization-intracytoplasmic sperm injection (IVF-ICSI) cycle outcomes indicated that the likelihood of livebirth increased in a log-linear fashion for an of AMH 2.94 and greater (13). Numerous additional studies have confirmed the correlation between higher AMH levels and superior ART cycle outcomes (14-16).

Ethnicity/race and age can have a substantial impact on ovarian reserve and thus, oocyte yield during ART cycles (1719). In this review, we intend to address how AMH may vary by ethnicity/race and varies according to age.

\section{METHODS}

A search was performed in Pubmed, The Cochrane Library, and Ovid-Medline. Phrases used in the search were suited for each individual database and included "AMH AND Caucasian quality," "AMH AND African-American," "AMH AND black," "AMH AND asian," "AMH AND race," "AMH AND ethnicity," "AMH AND age," "AMH AND adolescents," "AMH AND menopause," "Müllerian inhibitory substance/factor" AND Caucasian," "Müllerian inhibitory substance/factor AND African-American," "Müllerian inhibitory substance/factor AND black," "Müllerian inhibitory substance/factor AND Asian," "Müllerian inhibitory substance/factor AND race," "Müllerian inhibitory substance/factor AND ethnicity," "Müllerian inhibitory substance/factor AND age," "Müllerian inhibitory substance/factor AND adolescents," and "Müllerian inhibitory substance/factor AND menopause. Our search period spanned from 1946-2020. 3352 articles were found. These articles were then assessed for relevance and quality. Only studies published in English were included. Thirty-three of these studies were included as part of this review. A manual review of the references in each of the cited sources was performed to ensure that any relevant resource was not excluded.

The primary outcome of this review was to determine if $\mathrm{AMH}$ levels were correlated at any age range and were associated with any ethnic/racial group. Articles were selected as relevant if they were: 1) prospective studies, retrospective studies or metaanalyses involving females who underwent AMH assessment between birth until menopause. Studies were excluded if they were 1) case reports, non-systematic reviews, abstracts, expert opinion articles, 2) did not include an analysis of patients that had an AMH drawn or only analyzed patients that has other markers of ovarian reserve such as AFC or basal FSH.

\section{Ethnicity/Racial Differences}

As described in the following sections, ethnicity/race has been associated with substantial variations in AMH levels. Ethnicity/ race has typically been determined via patient self - reporting. However, genetic markers of ethnicity/race, also known as ancestry informative markers (AIMs), have been seen as a more objective method of ascertaining a patient's ethnicity. Olcha et al. looked at various ovarian reserve markers across various ethnicities based upon genetic ancestry via AIMs. This group showed that when controlling for age and body mass index (BMI), there is no variation in AMH based upon genetic markers of ethnicity (20). Determining ancestry via AIMs does have limitations which include the limited reference dataset of singlenucleotide polymorphisms that are used to identify genetic ethnicity (21). Consequentially, the use of AIMs may artificially contract the cohort of patients assigned to any one ethnicity. Therefore, we will assess the available literature on variations in $\mathrm{AMH}$ levels based upon patient-reported ethnicity.

\section{Caucasian}

Caucasian women are often the reference standard when assessing ethnic differences for a variety of parameters in infertility (22). Hence, we will first assess this ethnic/racial group. The first study looking at ethnic differences in $\mathrm{AMH}$ levels showed higher levels in Caucasian women compared to Black and Hispanic women after controlling for age, BMI, smoking, and HIV status (23). The second and one of the largest comparative assessments of ovarian reserve values among ethnicities was performed by Bliel et al. In this crosssectional study they assessed AMH levels in 947 women, of which 277 were white, 237 were African-American, 220 were Latina, and 213 were Chinese. Compared to all other ethnic groups, average AMH levels were consistently greater in white women, until age 35 (24). Substantial research has looked to variations in $\mathrm{AMH}$ levels in Caucasian women according to the presence of polycystic ovary syndrome (PCOS). Moy et al. performed a retrospective analysis looking at factors that affect $\mathrm{AMH}$ among numerous racial/ethnic groups. While age did correlate negatively with $\mathrm{AMH}$ among all ethnic groups, the prevalence of polycystic ovary syndrome, smoking, and elevated BMI correlated negatively only in Caucasian women (25). Of note, no distinction was made between infertility status of the women in any of the aforementioned studies. 


\section{African-American/Black}

Numerous studies have assessed AMH levels according to pre- or post-menopausal status. Based upon the study by Seifer et al., $\mathrm{AMH}$ was $25.2 \%$ lower in Black women compared to Caucasian women which was independent of age, BMI, smoking, and HIV status (23). In the study by Bleil et al., this group showed that their cohort of 237 Black and 213 Chinese women of younger and middle ages exhibited lower AMH levels compared to 227 white women. However, AMH levels in black women were higher than Latina and Chinese women of an older age (24). Marsh et al. looked at factors which lead to the variation in $\mathrm{AMH}$ levels in 1,654 African-American Women (AAW). Median $\mathrm{AMH}$ for $\mathrm{AAW}$ was $3.18 \mathrm{ng} / \mathrm{ml}$ and, in their age-adjusted model, they showed that BMI, use of hormonal contraceptives, and history of a thyroid disorder were negatively correlated with AMH levels. Furthermore, a history of abnormal bleeding during menses and oligomenorrhea was associated with higher AMH levels (26). Just as in Caucasian women, obesity, especially if patients were obese at 18 years of age had a significant negative correlation with AMH levels (27). This variation in AMH may be one contributing factor among several underlying the consistently lower live birth rates from assisted reproductive technologies observed in black women in the US (28). Looking at post-menopausal women, a cross-sectional study which included 671 women without a history of malignancy showed that race was not significantly associated with AMH levels (29). Furthermore, the study by Bleil et al. showed in a cohort of 947 women that $\mathrm{AMH}$ levels varied in a more consistent fashion across ethnicities among older women, especially when approaching the age of perimenopause (24). As with the studies in assessing AMH in Caucasian women, the studies assessing $\mathrm{AMH}$ levels in Black women did not distinguish between fertile and infertile populations.

\section{Hispanic}

As with black women, substantial differences have been noted in $\mathrm{AMH}$ levels with Hispanic women compared to other ethnic groups. Although the difference was not statistically significant, Seifer et al. showed a 24.6\% lower AMH level in Hispanic women than in Caucasian women (22). Bleil et al. showed that, across all ages, AMH was lower in a cohort of 220 Hispanic women compared to the 227 Caucasian women included in the study (24). Even among Hispanic women, substantial variations in $\mathrm{AMH}$ levels exist. In one study looking at women of Maya heritage in Mexico, these women were over five times more likely to have undetectable AMH levels compared to non-Maya women (30). Further research into regional or ancestral differences, especially throughout the Caribbean, Central, and South America may yield additional nuances in ovarian reserve levels in this population.

\section{Asian Populations}

Examining populations throughout Asia, there are two distinct trends seen. In a Chinese study looking at over 6,700 women from birth to the post-menopausal age, the authors noted a peak in AMH at age 18 with a consistent decline up until age 50 (31). When compared to Caucasian women, Nelson et al. recently noted that $\mathrm{AMH}$ levels were typically higher in Chinese women up until 25 years of age and then AMH levels tended to be less than Caucasian women after age 25 (32).

This is not the case in the South Asian population. Bhide looked at AMH variations in 865 women at a single fertility clinic and showed that despite higher AMH levels seen in South Asian patients compared to Caucasians, this difference disappeared in their multivariable analysis (33). These results are consistent with data from ART cycles which showed no significant difference between 236 Indian women and 236 Spanish women as far as AFC. AMH was slightly lower among Spanish women, but this was likely a factor of their older age (34). While differences may be present between younger Chinese and Caucasian women, this disparity disappears in older women and especially within other populations in Asia.

\section{Genetic and Environmental Underpinnings Behind Ethnic/Racial Differences}

Several groups have looked relationships between AMH levels and genetic variations among different ethnicities. Schuh-Huerta et al. looked at genetic variants and AMH levels in 232 Caucasian women and 200 African-American women. They showed two nominal genetic variants in the Jumonji, AT-rich interactive domain 2 (JARID2) gene and AMH levels in both ethnic groups (35). A separate group looked at fragile-X mental retardation (FMR1) and found that AMH level was associated with the number of repeats in the FMR1 gene $(\mathrm{p}<0.001)(36)$. This group correlated FMR1 variants with ethnicity and found substantial differences with Caucasians having the highest prevalence of abnormal alleles in this gene (37). BRCA1 has also been associated with lower AMH levels and BRCA1 is known to be more prevalent among non-Hispanic whites, and AfricanAmericans $(38,39)$. Currently, it is unclear if any of these genetic factors lead to lower AMH levels primarily as a result of ovarian aging or rather as a result of altered AMH expression/ secretion. Interestingly, at least one paper noted a paradoxical increase in AMH mRNA and protein in cumulus cells and follicular fluid as patient age increased (40).

Environmental factors may certainly also influence the ethnic variation of AMH. Numerous studies have shown a negative association between obesity, smoking and AMH levels (41-43). A multicenter study looking at the effect of BMI on the AMH levels of patients with PCOS and ovulatory controls, showed that BMI exhibited an inverse relationship with AMH regardless of patients age, race, smoking status and site in their regression analysis (44). This was seen in both cohorts. Plante et al. in their single-center cohort study looking at the effect of self-reported smoking history on AMH showed that current, but not past smokers have a $44 \%$ lower AMH level. Of note, they did not notice a dose-dependent response (45). Furthermore, these factors are known to be more prevalent in the AfricanAmerican and Hispanic populations (46). Additional nutritional factors may include vitamin D deficiency which is more prevalent among women of color and may in part contribute to lower serum AMH levels in these patient populations $(46,47)$. However, additional mechanistic studies of these factors are needed to confirm these environmental/ 
nutritional effects as direct drivers behind ethnic/racial disparities in AMH levels.

\section{Age-Related Differences \\ From Infancy to Adolescence}

$\mathrm{AMH}$ exhibits a progressive trend in the early stages of life. A Danish study from 2010 in examined AMH levels in 926 healthy females from birth to adulthood. They noted that AMH was undetectable in $54 \%$ of cord blood samples (i.e. from infants). $\mathrm{AMH}$ then increased from birth to 3 months up to $15 \mathrm{pmol} / \mathrm{liter}$ $(6.6 \mathrm{ng} / \mathrm{ml})$. Then from 8-25 years, AMH levels remained stable with the average level being $19.9 \mathrm{pmol} /$ liter $(8.8 \mathrm{ng} / \mathrm{ml})$ (48). This is consistent with a subsequent study which showed no difference in AMH levels in the American female population between 1021 years of age (49).

\section{Adulthood}

Concerning AMH levels in older women, Lie Fong et al. (45) expanded on the work done by the Hagen et al. (45) by looking at $\mathrm{AMH}$ levels from birth to older adult ages. They noted that AMH climbed to its maximum by 15.8 years of age and then remained stable until 25 years of age at which point it started a progressive decline to menopause. With older women, AMH was negatively correlated with age (50). This correlation was modeled in a linear fashion; however both Lie Fong et al. and La Marca et al. showed that the relationship is better fitted with a polynomial function $(50,51)$. Overall, the relationship between AMH and age cannot be considered linear throughout all age ranges.

When considering ovarian reserve and fertility, it is essential to assess when the decline in $\mathrm{AMH}$ becomes more precipitous. Wiweko et al. (49) did a retrospective study that looked at the relationship between various markers of ovarian reserve including FSH, AFC, and AMH. Serum AMH was shown to decline after 34 years of age. Bozkurt et al. (50) also noted an agerelated decline in $\mathrm{AMH}$ in both the fertile and infertile patients they studied. While they did not note an age at which the decline in $\mathrm{AMH}$ accelerated, patients 35 and older maintained a consistent age-related decline in $\mathrm{AMH}$ in both the fertile and infertile groups. Concerning the magnitude of this decline in the infertile population, the rate of decline of the median $\mathrm{AMH}$ was noted to decrease in a retrospective review of over 17,000 infertile women from 0.2 to $0.1 \mathrm{ng} / \mathrm{ml}$ per year after age 35 (52). Please see Figure 1. A subsequent prospective study comparing infertile women younger than 40 and fertile controls of the same age range noted an approximately 6\% decrease in $\mathrm{AMH}$ per year (53). These findings supplement the findings in the infertile population from Seifer et al. (52). Thus, there are age-specific values that are clinically useful to keep in mind when using $\mathrm{AMH}$ in the infertile population to determine the status of a woman's ovarian reserve. Of note, a retrospective study of healthy, reproductive age women showed that even at younger ages, concerningly low AMHs were noted. This suggests that even young women do have some risk for low ovarian reserve and that caution is needed when counseling patients on fertility planning (54).

\section{Clinical Significance}

Our knowledge of the ethnicity- and age-related variation in $\mathrm{AMH}$ allows for giving proper context to patients. While patients of various ethnicities may exhibit lower levels of $\mathrm{AMH}$, patients can be reassured that, the general trend of $\mathrm{AMH}$ with age appears to be consistent among ethnicities. Furthermore, the age-based variation is an effective tool to gauge possible oocyte yield for patients undergoing treatment with assisted reproductive

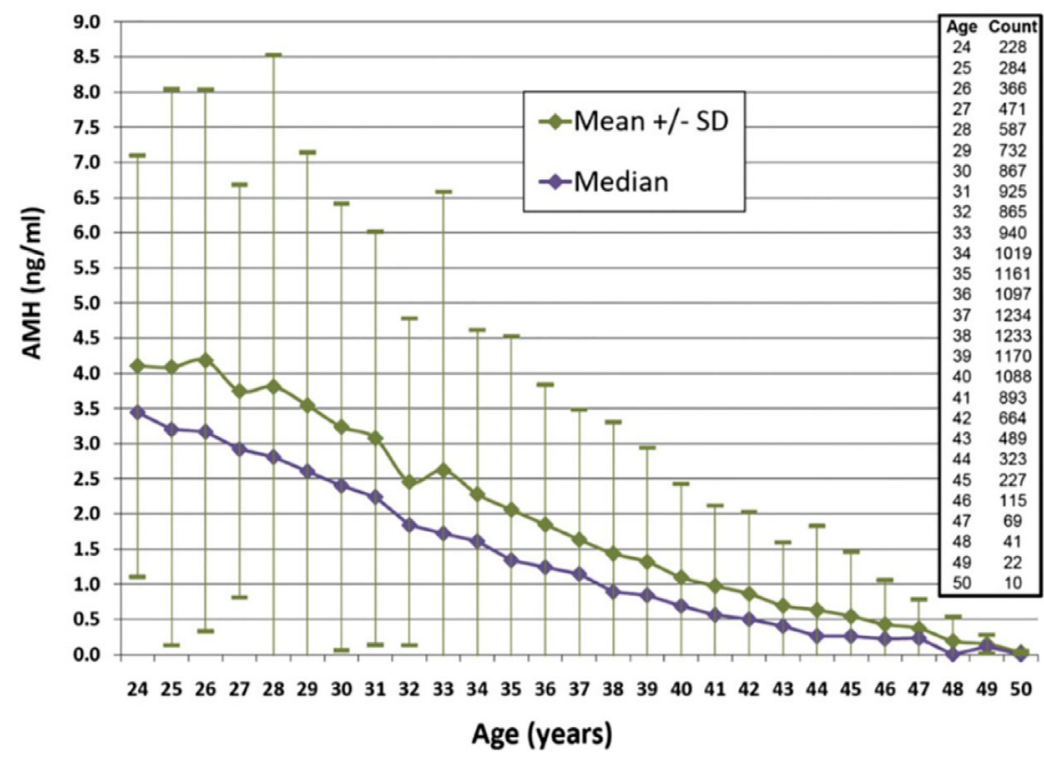

FIGURE 1 | AMH levels according to age for women 24-50 years of age. Median values are shown with standard deviations. Reproduced with permission from Seifer et al. Age-specific serum anti-Mullerian hormone values for 17,120 women presenting to fertility centers within the United States. Fertil Steril. 2011 ; 95 (2): 747-50. 
technologies (55). The age-dependent decline in AMH can also assist in gauging response in women undergoing fertility preservation (55).

\section{CONCLUSIONS}

$\mathrm{AMH}$, as a mainstay of ovarian reserve testing, shows widespread ethnicity/race- and age-based variation. Variations according to ethnicity/race may be dependent on additional factors such as BMI, PCOS, socioeconomic status, environmental/nutritional factors such as vitamin D status among other aspects. However, the effect of age on AMH appears to be consistent among various ethnicities/races and thus, age-specific AMH

\section{REFERENCES}

1. Seifer DB, MacLaughlin DT, Christian BP, Feng B, Shelden RM. Early follicular serum mullerian-inhibiting substance levels are associated with ovarian response during assisted reproductive technology cycles. Fertil Steril (2002) 77(3):468-71. doi: 10.1016/S0015-0282(01)03201-0

2. Cate RL, Mattaliano RJ, Hession C, Tizard R, Farber NM, Cheung A, et al. Isolation of the bovine and human genes for Mullerian inhibiting substance and expression of the human gene in animal cells. Cell (1986) 45(5):685-98. doi: 10.1016/0092-8674(86)90783-X

3. Baarends WM, Uilenbroek JT, Kramer P, Hoogerbrugge JW, van Leeuwen EC, Themmen AP, et al. Anti-mullerian hormone and anti-mullerian hormone type II receptor messenger ribonucleic acid expression in rat ovaries during postnatal development, the estrous cycle, and gonadotropininduced follicle growth. Endocrinology (1995) 136(11):4951-62. doi: 10.1210/ endo.136.11.7588229

4. Jost A. Problems of fetal endocrinology: the gonadal and hypophyseal hormones. Recent Prog Horm Res (1953) 8:379-418.

5. Lee MM, Donahoe PK. Mullerian inhibiting substance: a gonadal hormone with multiple functions. Endocr Rev (1993) 14(2):152-64. doi: 10.1210/ er.14.2.152

6. Weenen C, Laven JS, Von Bergh AR, Cranfield M, Groome NP, Visser JA, et al. Anti-Mullerian hormone expression pattern in the human ovary: potential implications for initial and cyclic follicle recruitment. Mol Hum Reprod (2004) 10(2):77-83. doi: 10.1093/molehr/gah015

7. Seifer DB, MacLaughlin DT, Penzias AS, Behrman HR, Asmundson L, Donahoe PK, et al. Gonadotropin-releasing hormone agonist-induced differences in granulosa cell cycle kinetics are associated with alterations in follicular fluid mullerian-inhibiting substance and androgen content. J Clin Endocrinol Metab (1993) 76(3):711-4. doi: 10.1210/jcem.76.3.8445031

8. Tal R, Seifer DB. Ovarian reserve testing: a user's guide. Am J Obstet Gynecol (2017) 217(2):129-40. doi: 10.1016/j.ajog.2017.02.027

9. Fleming R, Seifer DB, Frattarelli JL, Ruman J. Assessing ovarian response: antral follicle count versus anti-Mullerian hormone. Reprod BioMed Online (2015) 31(4):486-96. doi: 10.1016/j.rbmo.2015.06.015

10. van Disseldorp J, Lambalk CB, Kwee J, Looman CW, Eijkemans MJ, Fauser $\mathrm{BC}$, et al. Comparison of inter- and intra-cycle variability of anti-Mullerian hormone and antral follicle counts. Hum Reprod (2010) 25(1):221-7. doi: 10.1093/humrep/dep366

11. de Koning $\mathrm{CH}$, McDonnell J, Themmen AP, de Jong FH, Homburg R, Lambalk CB. The endocrine and follicular growth dynamics throughout the menstrual cycle in women with consistently or variably elevated early follicular phase FSH compared with controls. Hum Reprod (2008) 23 (6):1416-23. doi: 10.1093/humrep/den092

12. DB Seifer, R Tal eds. Anti-Mullerian hormone: biology, role in ovarian function and clinical significance. New York: Nova (2016).

13. Brodin T, Hadziosmanovic N, Berglund L, Olovsson M, Holte J. Antimullerian hormone levels are strongly associated with live-birth rates values provide clinical context particularly in the infertile woman. Age is a strong common denominator that influences the reproductive life of women regardless of race or origin. Future research may shed light on how to mitigate the effects of ethnicity/race and age upon AMH as a reflection of ovarian reserve. This future work could potentially have a favorable impact on ART and fertility/family planning in general.

\section{AUTHOR CONTRIBUTIONS}

AK and DS contributed equally to the article search, analysis, review, and compilation of relevant articles for this review. All authors contributed to the article and approved the submitted version.

after assisted reproduction. J Clin Endocrinol Metab (2013) 98(3):1107-14. doi: 10.1210/jc.2012-3676

14. Reichman DE, Goldschlag D, Rosenwaks Z. Value of antimullerian hormone as a prognostic indicator of in vitro fertilization outcome. Fertil Steril (2014) 101(4):1012-8.e1. doi: 10.1016/j.fertnstert.2013.12.039

15. Arce JC, La Marca A, Mirner Klein B, Nyboe Andersen A, Fleming R. Antimullerian hormone in gonadotropin releasing-hormone antagonist cycles: prediction of ovarian response and cumulative treatment outcome in good-prognosis patients. Fertil Steril (2013) 99(6):1644-53. doi: 10.1016/ j.fertnstert.2012.12.048

16. Nelson SM, Klein BM, Arce JC. Comparison of antimullerian hormone levels and antral follicle count as predictor of ovarian response to controlled ovarian stimulation in good-prognosis patients at individual fertility clinics in two multicenter trials. Fertil Steril (2015) 103(4):923-30.el. doi: 10.1016/ j.fertnstert.2014.12.114

17. Patel AP, Patel JA, Cruz M, Gupte-Shah A, Garcia Velasco JA, Banker MR. Ethnicity is an independent predictor of IVF-ICSI outcome: a study of 5,549 cycles in Spain and India. Gynecol Endocrinol (2016) 32(10):819-22. doi: $10.1080 / 09513590.2016 .1188377$

18. Tabbalat AM, Pereira N, Klauck D, Melhem C, Elias RT, Rosenwaks Z. Arabian Peninsula ethnicity is associated with lower ovarian reserve and ovarian response in women undergoing fresh ICSI cycles. J Assist Reprod Genet (2018) 35(2):331-7. doi: 10.1007/s10815-017-1071-7

19. Yavas Y. Curvilinear relationship between age and assisted reproduction technique success: retrospective analyses of US National ART Surveillance System data from 2010-2014. Reprod BioMed Online (2017) 35(6):657-68. doi: 10.1016/j.rbmo.2017.07.018

20. Olcha M, Franasiak JM, Shastri S, Molinaro TA, Congdon H, Treff NR, et al. Genotypically determined ancestry across an infertile population: ovarian reserve and response parameters are not influenced by continental origin. Fertil Steril (2016) 106(2):475-80. doi: 10.1016/j.fertnstert.2016.03.052

21. Mersha TB, Abebe T. Self-reported race/ethnicity in the age of genomic research: its potential impact on understanding health disparities. Hum Genomics (2015) 9(1).

22. Armstrong A, Plowden TC. Ethnicity and assisted reproductive technologies. Clin Pract (Lond) (2012) 9(6):651-8. doi: 10.2217/cpr.12.65

23. Seifer DB, Golub ET, Lambert-Messerlian G, Benning L, Anastos K, Watts $\mathrm{DH}$, et al. Variations in serum mullerian inhibiting substance between white, black, and Hispanic women. Fertil Steril (2009) 92(5):1674-8. doi: 10.1016/ j.fertnstert.2008.08.110

24. Bleil ME, Gregorich SE, Adler NE, Sternfeld B, Rosen MP, Cedars MI. Race/ethnic disparities in reproductive age: an examination of ovarian reserve estimates across four race/ethnic groups of healthy, regularly cycling women. Fertil Steril (2014) 101(1):199-207. doi: 10.1016/ j.fertnstert.2013.09.015

25. Moy V, Jindal S, Lieman H, Buyuk E. Obesity adversely affects serum antimullerian hormone (AMH) levels in Caucasian women. J Assist Reprod Genet (2015) 32(9):1305-11. doi: 10.1007/s10815-015-0538-7 
26. Marsh EE, Bernardi LA, Steinberg ML, de Chavez PJ, Visser JA, Carnethon MR, et al. Novel correlates between antimullerian hormone and menstrual cycle characteristics in African-American women (23-35 years-old). Fertil Steril (2016) 106(2):443-50.e2. doi: 10.1016/j.fertnstert.2016.04.008

27. Bernardi LA, Carnethon MR, de Chavez PJ, Ikhena DE, Neff LM, Baird DD, et al. Relationship Between Obesity and Anti-Müllerian Hormone in Reproductive-Aged African-American Women. Obesity (Silver Spring) (2017) 25(1):229-35. doi: 10.1002/oby.21681

28. Seifer DB, Simsek B, Wantman E, Kotlyar AM. Status of Racial Disparities Between Black and White Women Undergoing Assisted Reproductive Technology in the US. Reprod Biol Endocrinol (2020) 18:113. doi: 10.1186/ s12958-020-00662-4

29. Jung S, Allen N, Arslan AA, Baglietto L, Brinton LA, Egleston BL, et al. Demographic, lifestyle, and other factors in relation to antimullerian hormone levels in mostly late premenopausal women. Fertil Steril (2017) 107(4):101222.e2. doi: 10.1016/j.fertnstert.2017.02.105

30. Kyweluk MA, Sievert LL, Huicochea-Gomez L, Cahuich-Campos D, McDade T, Brown DE. Variation in levels of AMH among Maya and non-Maya women in Campeche, Mexico. Am J Phys Anthropol (2018) 167(2):282-90. doi: 10.1002/ ajpa.23627

31. Cui L, Qin Y, Gao X, Lu J, Geng L, Ding L, et al. Antimullerian hormone: correlation with age and androgenic and metabolic factors in women from birth to postmenopause. Fertil Steril (2016) 105(2):481-5.e1. doi: 10.1016/ j.fertnstert.2015.10.017

32. Nelson SM, Aijun S, Ling Q, Tengda X, Wei X, Yan D, et al. Ethnic discordance in serum anti-Müllerian hormone in healthy women: a population study from China and Europe. Reprod BioMed Online (2019) 40 (3):461-7. doi: 10.1016/j.rbmo.2019.11.013

33. Bhide P, Gudi A, Shah A, Homburg R. Serum anti-Mullerian hormone levels across different ethnic groups: a cross-sectional study. Bjog (2015) 122 (12):1625-9. doi: 10.1111/1471-0528.13103

34. Iglesias C, Banker M, Mahajan N, Herrero L, Meseguer M, Garcia-Velasco JA. Ethnicity as a determinant of ovarian reserve: differences in ovarian aging between Spanish and Indian women. Fertil Steril (2014) 102(1):244-9. doi: 10.1016/j.fertnstert.2014.03.050

35. Schuh-Huerta SM, Johnson NA, Rosen MP, Sternfeld B, Cedars MI, Reijo Pera RA. Genetic variants and environmental factors associated with hormonal markers of ovarian reserve in Caucasian and African American women. Hum Reprod (2012) 27(2):594-608. doi: 10.1093/ humrep/der391

36. Gleicher N, Weghofer A, Oktay K, Barad D. Relevance of triple CGG repeats in the FMR1 gene to ovarian reserve. Reprod BioMed Online (2009) 19 (3):385-90. doi: 10.1016/S1472-6483(10)60173-3

37. Gleicher N, Weghofer A, Barad DH. Effects of race/ethnicity on triple CGG counts in the FMR1 gene in infertile women and egg donors. Reprod BioMed Online (2010) 20(4):485-91. doi: 10.1016/j.rbmo.2009.12.017

38. Titus S, Li F, Stobezki R, Akula K, Unsal E, Jeong K, et al. Impairment of BRCA1-related DNA double-strand break repair leads to ovarian aging in mice and humans. Sci Transl Med (2013) 5(172):172ra21. doi: 10.1126/ scitranslmed. 3004925

39. John EM, Miron A, Gong G, Phipps AI, Felberg A, Li FP, et al. Prevalence of pathogenic BRCA1 mutation carriers in 5 US racial/ethnic groups. Jama (2007) 298(24):2869-76. doi: 10.1001/jama.298.24.2869

40. Kedem A, Yung Y, Yerushalmi GM, Haas J, Maman E, Hanochi M, et al. Anti Mullerian Hormone (AMH) level and expression in mural and cumulus cells in relation to age. J Ovarian Res (2014) 7:113. doi: 10.1186/s13048-014-0113-3

41. Buyuk E, Seifer DB, Illions E, Grazi RV, Lieman H. Elevated body mass index is associated with lower serum anti-mullerian hormone levels in infertile women with diminished ovarian reserve but not with normal ovarian reserve. Fertil Steril (2011) 95(7):2364-8. doi: 10.1016/j.fertnstert.2011.03.081

42. Sowers MR, McConnell D, Yosef M, Jannausch ML, Harlow SD, Randolph JFJr. Relating smoking, obesity, insulin resistance, and ovarian biomarker changes to the final menstrual period. Ann N Y Acad Sci (2010) 1204:95-103. doi: 10.1111/j.1749-6632.2010.05523.x

43. Freeman EW, Gracia CR, Sammel MD, Lin H, Lim LC, Strauss JF3rd. Association of anti-mullerian hormone levels with obesity in late reproductive-age women. Fertil Steril (2007) 87(1):101-6. doi: 10.1016/ j.fertnstert.2006.05.074

44. Jaswa EG, Rios JS, Cedars MI, Santoro NF, Pavone MEG, Legro RS, et al. Increased Body Mass Index Is Associated With A Nondilutional Reduction in Antimüllerian Hormone. J Clin Endocrinol Metab (2020) 105(10):3234-42. doi: $10.1210 /$ clinem/dgaa436

45. Plante BJ, Cooper GS, Baird DD, Steiner AZ. The impact of smoking on antimüllerian hormone levels in women aged 38 to 50 years. Menopause (2010) 17(3):571-6. doi: 10.1097/gme.0b013e3181c7deba

46. Tal R, Seifer DB. Potential Mechanisms for Racial and Ethnic Differences in Antimüllerian Hormone and Ovarian Reserve. Int J Endocrinol (2013) 2013:818912. doi: 10.1155/2013/818912

47. Merhi ZO, Seifer DB, Weedon J, Adeyemi O, Holman S, Anastos K, et al. Circulating vitamin D correlates with serum antimullerian hormone levels in late-reproductive-aged women: Women's Interagency HIV Study. Fertil Steril (2012) 98(1):228-34. doi: 10.1016/j.fertnstert. 2012.03.029

48. Hagen CP, Aksglaede L, Sorensen K, Main KM, Boas M, Cleemann L, et al. Serum levels of anti-Mullerian hormone as a marker of ovarian function in 926 healthy females from birth to adulthood and in 172 Turner syndrome patients. J Clin Endocrinol Metab (2010) 95(11):5003-10. doi: 10.1210/ jc.2010-0930

49. Elchuri SV, Patterson BC, Brown MR, Buchanan I, Mertens AC, Meacham LR. Anti-Mullerian hormone levels in American girls by age and race/ ethnicity. J Pediatr Endocrinol Metab (2015) 28(1-2):189-93. doi: 10.1515/ jpem-2014-0242

50. Lie Fong S, Visser JA, Welt CK, de Rijke YB, Eijkemans MJC, Broekmans FJ, et al. Serum Anti-Müllerian Hormone Levels in Healthy Females: A Nomogram Ranging from Infancy to Adulthood. J Clin Endocrinol Metab (2012) 972012:4650-5. doi: 10.1210/jc.2012-1440

51. La Marca A, Sighinolfi G, Giulini S, Traglia M, Argento C, Sala C, et al. Normal serum concentrations of anti-Mullerian hormone in women with regular menstrual cycles. Reprod BioMed Online (2010) 21(4):463-9. doi: 10.1016/j.rbmo.2010.05.009

52. Seifer DB, Baker VL, Leader B. Age-specific serum anti-Mullerian hormone values for 17,120 women presenting to fertility centers within the United States. Fertil Steril (2011) 95(2):747-50. doi: 10.1016/ j.fertnstert.2010.10.011

53. Khan HL, Bhatti S, Suhail S, Gul R, Awais A, Hamayun H, et al. Antral follicle count (AFC) and serum anti-Mullerian hormone (AMH) are the predictors of natural fecundability have similar trends irrespective of fertility status and menstrual characteristics among fertile and infertile women below the age of 40 years. Reprod Biol Endocrinol (2019) 17(1):20. doi: 10.1186/ s12958-019-0464-0

54. Shebl O, Ebner T, Sir A, Schreier-Lechner E, Mayer RB, Tews G, et al. Agerelated distribution of basal serum AMH level in women of reproductive age and a presumably healthy cohort. Fertil Steril (2011) 95(2):832-4. doi: 10.1016/j.fertnstert.2010.09.012

55. Dewailly D, Andersen CY, Balen A, Broekmans F, Dilaver N, Fanchin R, et al. The physiology and clinical utility of anti-Mullerian hormone in women. Hum Reprod Update (2014) 20(3):370-85. doi: 10.1093/humupd/dmt062

Conflict of Interest: DS receives royalties from a licensing agreement between Beckman-Coulter and Rutger's Medical School/MGH for the use of AMH in determining ovarian reserve.

The remaining author declares that the research was conducted in the absence of any commercial or financial relationships that could be construed as a potential conflict of interest.

Copyright (๑) 2021 Kotlyar and Seifer. This is an open-access article distributed under the terms of the Creative Commons Attribution License (CC BY). The use, distribution or reproduction in other forums is permitted, provided the original author(s) and the copyright owner(s) are credited and that the original publication in this journal is cited, in accordance with accepted academic practice. No use, distribution or reproduction is permitted which does not comply with these terms. 